I had already considered that possibility and came to the conclusion that such an error could not be serious in my measurements. In the first place, I did not introduce any substance until the thermometer was either stationary or changing in such a steady way that the change during the solution could be accounted for and corrected with very few exceptions, which exceptions are readily seen in the high values of their corrections. These high values are due to the long time needed for the solution of the less soluble bodies at low temperatures.

Moreover, the effect of imperfect elasticity in the bulb of the thermometer would seem to be such as to always reduce the rise of the mercury, but in many cases the rise is too great. Besides, in some cases, the measurements of a whole series are very satisfactory.

I do not think that there is any evidence of a disturbance coming from the elasticity of the bulb.

On the other hand, in regard to the imperfect elasticity of thermometer bulb in a series of experiments such as Noyes and Abbot made, 'it is easy to see that imperfect elasticity of the bulb might prevent the use of a thermometer like that of Beckmann, for in their experiments the thermometer had to show, with great precision and throughout a considerable period of time, a certain constant temperature, and not a variation of temperature throughout a very short time, as it had to do in my case.

Finally I would repeat that my object was to determine the molecular weights of carbon compounds at the ordinary temperatures, $25^{\circ}-35^{\circ}$, as I stated in the article reviewed, and not to determine the effect of temperature on the molecular raising, as the reviewer seemed to assume.

Rutgers College, May ir, 1898 .

\title{
NOTE ON DROWN'S METHOD OF DETERMINING SILICON IN STEEL.
}

By George ACchy.

Received May 24,1898 .

I determining silicon in steel by Drown's method there is some reason to believe that sometimes not all the silicon is obtained.

1 Ztschr. phys. Chem., 23, 56. 
Says Dr. Dudley :' "Our observations point to the view that the difficulty of insufficient dehydration is due to the separation of iron salts as the sulphuric acid concentrates. These salts enclose gelatinous silica, and prevent the dehydrating acid from getting at it. Unless great pains are taken, therefore, to secure this contact by sufficient stirring, the results will be low."

In this connection it is perhaps worthy of note that if the evaporation be performed with aqua regia and sulphuric acid instead of with nitric and sulphuric acids (boiled down rapidly in a porcelain casserole on a very hot plate, and with a watchglass suspended above casserole by small pieces of bent glass rod), the iron salt is kept in solution till the very last moment when it suddenly crystallizes out and the fumes of sulphuric acid appear, almost at once if the plate be very hot, and very soon afterward if not so hot; and it is therefore a reasonable supposition that this method of procedure is more favorable to a complete dehydration of the silica than the usual nitro-sulphuric process. in which the iron sulphate begins to separate out long before the expulsion of the nitric acid. If the additional precaution be taken to make a second evaporation before filtering, it may in the writer's opinion be confidently expected that no notable amount of silica will escape dehydration. A number of tests were made by evaporating the filtrates, in steels containing about 0.25 per cent. silicon, without getting additional silicon more than 0.005 per cent. which is an amount that may be ignored in ordinary technical work, on steels of that percentage (0.25). A steel which gave 0.I22 by one evaporation, gave 0.126 upon repeating the test and making two evaporations before filtering.

4.6667 grams are taken in a porcelain casserole, and treated with fifty cc. of a mixture of $500 \mathrm{cc}$. of nitric acid (two parts acid to three parts water), $300 \mathrm{cc}$. of strong sulphuric acid, and 200 cc. of water, equivalent to twenty-five cc. nitric acid (two to three), fifteen cc. strong sulphuric acid, and ten cc. water to a test. When the steel has dissolved, fifteen cc. of strong hydrochloric acid are added, the watch-glass suspended above the casserole by three small bent glass rods, and the liquid boiled down rapidly, using a very hot iron plate.

1 This Journal, Ig, I06. 
Very noteworthy is the ease and rapidity with which this evaporation is made. Unlike the nitro-sulphuric acid boiling down, the boiling proceeds very quietly and without any bumping and spattering even at the moment of solidification and after, so that no attention is required.

In high carbon steels the silica is brown from undissolved carbon which, however, upon ignition immediately burns off.

I ABORATORY OF THE KEYSTONE SAW WORKS,

Phitadelphia, PA.

\section{NOTE.}

Preparation of Sodium Benzenesulphonate.' - The directions given by Gattermann in his "Praxis des organischen Chemikers" are usually so accurate that it seems desirable to call attention to a needed alteration in the details of the method for preparing sodium benzenesulphonate (p. 2I7).

Repeated experiments show that by adding the products of sulphonation, when using fuming sulphuric acid (sp. gr. I.87), to three or four times the volume of saturated salt solution, as he directs, a sulphonate, containing on an average thirty-seven per cent. of sodium chloride, is obtained.

This contamination may be avoided almost entirely by using four volumes of a less concentrated salt solution. One showing a specific gravity of I.I 5 I at I $8^{\circ}$ gives the best results.

The advantage of the modified method is seen from the details of two preparations, in each of which twenty grams of benzene and seventy-five grams of sulphuric acid ( $\mathrm{sp} . \mathrm{gr}$. I.87), were used. In No. I, $240 \mathrm{cc}$. of a saturated salt solution (sp. gr. I.204), in No. 2, $254 \mathrm{cc}$. of a solution (sp. gr. I.I5I), were used. The yield of crystals, after filtering through asbestos and drying on a porous plate, was :

\begin{tabular}{cccr} 
& & \multicolumn{2}{c}{ Composition, in grams. } \\
No. & Yield in grams. & $\mathrm{C}_{6} \mathrm{H}_{6} \mathrm{SO}_{3} \mathrm{Na}$. & NaCl. \\
1 & 75 & 48.1 & 26.9 \\
2 & 46 & 45.6 & 0.4
\end{tabular}

With a slight sacrifice in yield a high degree of purity is obtained.

The method outlined by Prof. W. A. Noyes, "Organic

1 Read before the Cincinnati Section, April 15,1898 . 